\title{
Mechanical and Dynamic Characterization of Sustainable Composites Based on Food Packaging Waste
}

\author{
M G Nassef ${ }^{1}$, I El-Galy ${ }^{1}$ and A Hassanin ${ }^{2}$ \\ 1 Production Engineering Department, Alexandria University, 21544 Alexandria, Egypt \\ 2 Textile Engineering Department, Alexandria University, 21544 Alexandria, Egypt
}

\begin{abstract}
Composites made from food packaging waste are recently introduced to the industry as promising materials that aim to reduce the environmental waste and to develop cost effective products. They possess good physical properties, which makes them potential competitors to wood based composite structures such as commercial particleboard (PB), and medium density fiberboard (MDF). Despite the expected advantages, the mechanical and dynamic behaviour of this genuine structure still needs to be studied and tested to evaluate its suitability for light weight structure applications. Experimental modal analysis is conducted on specimens made of food packaging waste, sandwich structured packaging waste with woven glass-fiber skin, MDF and PB. The dynamic testing results show superior damping ratio for the food packaging waste composites compared to the wood-based specimens. Natural frequencies exhibit comparable dynamic stiffness with respect to MDF, and PB. Further investigation has been made to evaluate both the modulus of rapture and the static stiffness of the material by conducting flexural tests on all specimens. Sandwich structure produced from food packaging waste and veneered with woven glass-fiber fabric exhibit excellent magnitudes for the modulus of rupture in addition the highest damping ratio.
\end{abstract}

\section{Introduction}

While traditional wood-based materials such as particle board (PB) and plywood (PW) have proven their suitability for use in construction industry since decades, a wide variety of composite materials are currently taking over in many structural applications. Medium density fiberboard (MDF), high density fiberboard (HDF) and wood plastic composites (WPC) represent good examples for these relatively new families, where performance, and not only cost, is the decisive selection factor. These materials are becoming important structural elements in civil construction [1], architecture [2], as well as, in automotive industry as a lightweight material used for reducing fuel and $\mathrm{CO}_{2}$ emissions [3,4]. These materials are mainly comprised of a blend of polymeric materials (thermoplastics and thermosets) with reinforcing cellulosic and/or lignocellulosic fibers. Adhesives, stabilizers, fire retardants and colouring agents are also used as additives [5, 6]. Different combinations of constituents and production parameters (e.g. size, orientation, pressure, temperature) have been used to manufacture and test these structural composites under different thermo-mechanical, chemical and environmental conditions [7].

Encountered problems during the service life of these composites raise questions regarding their sustainability and reliability. For instance, WPC are prone to thermal degradation [8] and biological decay from different sources such as insects, bacteria, and fungus [9]. Special precautions in the design and material selection of WPC elements results in expensive or inapplicable products. Another aspect that influence the durability and usability of $\mathrm{WPC} / \mathrm{MDF} / \mathrm{HDF}$ products is the dimensional inaccuracies and the geometrical distortions caused by their high readiness for moister absorption and swelling $[10,11]$. Therefore, alternatives to these materials in the industrial applications are under focus of study by researchers.

Given the current concerns regarding environmental hazards, food packaging waste from paperboard/polymeric based materials has been viewed as unexploited material resource. One example is Tetra Pak ${ }^{\circledR}$ (TP) which is used in the industry of beverage carton manufacturing. The number of Tetra Pak packages sold in 2016 was around 188 billion packages [12]. Only one fourth of them were recycled in the same year.

Recent attempts to recycle TP cartons have been considered by different research and industrial bodies [13]. Separation of the cellulosic paperboard in a wet process and pyrolysis of the remaining aluminium/polyethylene is a complex inefficient process $[14,15]$. Recycling the shredded TP laminate or the ground material is less complex and more efficient from production point of view.

A recent attempt was made to recycle the Tetra Pak waste, mixed with wool fibers and selected binders, into novel bio composite specimens [16]. Specimens from the 
material were manufactured and tested using flexure test and internal bonding test. Modulus of Rupture (MOR) and internal bond strength values of Tetra Pak composites with different skin materials are found to be higher than that of commercial particleboard specimens [16].

A comparative study between commercial particleboard specimens and composite specimens made of ground Tetra Pak blended with different percentages of natural short fiber wool was conducted to evaluate the physical and biological behaviour [17]. Resistance to termite test showed that Tetra Pak based composites with high wool fiber percentages showed superior durability as compared to wood. Furthermore, Tetra Pak/wool-based composites manifested higher resistance to water absorption compared to wood-based PB specimens when submerged in a water bath at room temperature for different time spans. Another research effort investigated the biological and thermal degradation of individual materials in shredded TP composites [18].

One previous work explored the efficiency of textile reinforced Tetra Pak waste material as a thermal insulator in buildings [19]. It was found that trapped air within the recycled fibers improved the insulation capabilities of the Tetra Pak composites.

The economic advantage and availability of the proposed TP waste-based material compared with the more expensive materials, such as WPC/MDF/HDF, provide increasing interest of research to envisage their thermomechanical, dynamic and biological properties in correlation with the possible manufacturing variants and production parameters.

Among the proposed applications for the developed Tetra Pak waste-based composites is to serve as a damper or isolator under dynamic loading conditions. This challenging task requires the assessment of the dynamic characteristics such as damping capacity, which plays a crucial role at resonant loading conditions, and in controlling the transmissibility of vibration.

Previous studies showed that the damping of the polymer-based composites is governed by the viscoelastic behaviour in the matrix and at the interface between the matrix and the reinforcement [20]. The internal mechanisms that contribute to the total material damping are based on the type and size of reinforcement, the relative proportions of matrix and reinforcement, and the orientation of the reinforcing material.

Modal analysis is a methodology used in a wide spectrum of applications to determine the dynamic characteristics of structures [21, 22], in material characterization [23-25], damage detection in components [26, 27], and reliability evaluation [28]. The obtained dynamic characteristics from modal analysis are eigen frequencies, mode shapes, and material/structure damping.

The aim of this work is to investigate the current level of the proposed material's dynamic response and to optimize its behaviour for industrial applications. In this work, experimental modal analysis is used to determine the dynamic characteristics of the proposed composites. Their results are, then, compared with those from woodbased products, namely, particleboard, and medium density fiberboard MDF. This is essential to ensure the suitability and competency of the proposed material for light weight structure applications.

Because the dynamic characteristics are strongly connected with the mechanical properties of a material, mechanical testing is conducted on the specimens to determine the modulus of elasticity and modulus of rapture. This provides a better understanding of the obtained dynamic characteristics results. Also, the fracture mode of each specimen is examined for justification.

\section{Materials and Methods}

\subsection{Sample preparation}

Two types of specimens are fabricated from food packaging waste in this work. The first type is $100 \%$ waste from Tetra Pak (TP). The laminated composite structure consists of aluminium foil (5\%) covered from both sides by four polyethylene layers (20\%), and two paperboard layers (75\%) [29]. The second type is a sandwich structured specimen which is basically a TP, as a core, with double sided surface layers (skin) from fiber glass (TPFG). A brief description of the produced test specimens is shown in table 1 .

Specimens are prepared from discarded, postconsumer, packaging cartons, which are shredded to small pieces as shown in figure 1 . Each specimen is shaped using a two-stage hot pressing process into a mould of ( $350 \mathrm{~mm}$ by $250 \mathrm{~mm}$ ) as shown in figures 2 and 3 .

The first stage is executed at $190-200^{\circ} \mathrm{C}$ for $5 \mathrm{~min}$ under a pressure of 5 bars to eliminate the air gap between the shredded pieces in the mould. In the second stage, the material is heated at $190-200^{\circ} \mathrm{C}$ for 3 min under a 15-bar pressure. The amount of TP shreds is adjusted to reach the target density of $0.8 \mathrm{~g} / \mathrm{cm}^{3}$ and a thickness of $10 \mathrm{~mm}$ under the operating pressure. The polyethylene layers start to fuse and act as an adhesive inside each shredded piece and between the pile of pieces in the mould. This stage is crucial to produce reliable and coherent laminated structure.

Table 1. Selected sample material groups and their description.

\begin{tabular}{cc} 
Coding & Description \\
\hline TP & $100 \%$ food packaging waste (Tetra Pack $\left.{ }^{\circledR}\right)$ \\
TPFG & $\begin{array}{c}\text { Sandwich structure with skin made of glass } \\
\text { fabric and core from } 100 \% \text { food packaging } \\
\left.\text { waste (Tetra Pack }{ }^{\circledR}\right)\end{array}$ \\
\hline MDF & $\begin{array}{c}\text { Commercial wood-based boards with medium } \\
\text { density fibers compaction }\end{array}$ \\
\hline PB & Commercial Particleboard \\
\hline
\end{tabular}




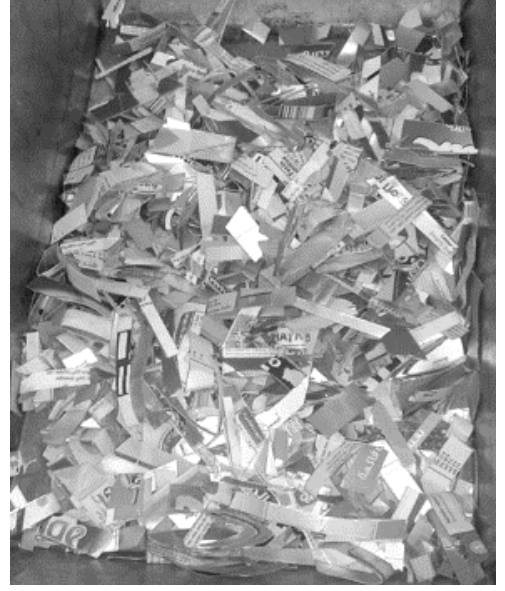

Figure 1. Shredded food packaging waste from Tetra Pak.

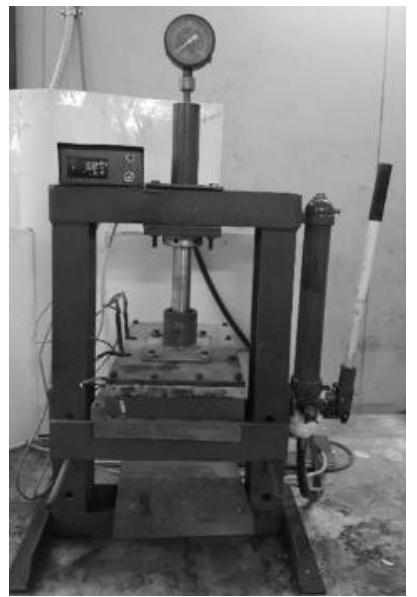

Figure 2. Press machine for specimen preparation.

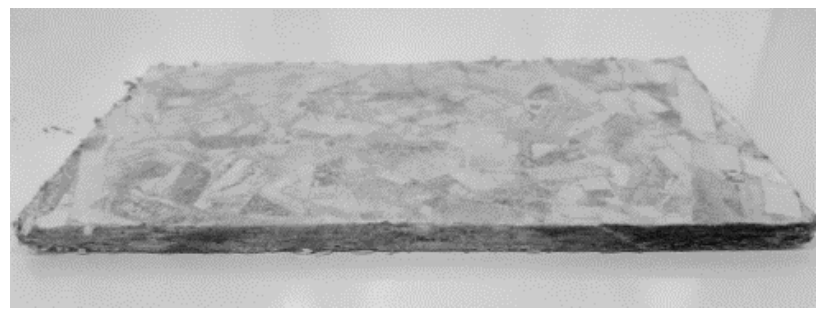

Figure 3. Tetra Pak (TP) final product.

\subsection{Modal analysis}

Experimental modal analysis is conducted on four sets of specimens; TP, TPFG, MDF and PB to calculate their dynamic characteristics. Free boundaries vibration testing is conducted on specimens by hanging them using soft cords. In this way, the results of the flexible body modes of vibration are obtained regardless influences from the fixation method itself [30]. Each specimen is excited by a small impulse from an impact excitation hammer and the impulse signal is measured using a force transducer (B\&K Type 8200) as shown in figure 4 .

The corresponding response is measured using a vibration sensor (Piezoelectric Uniaxial Accelerometer) attached by wax to the specimen. Both signals of the impulse and the sample response are processed using a four-channel signal analyzer (B\&K Type 3022) equipped by Acquisition Front-End (B\&K Type 2825). Signals are conditioned and processed by applying antialiasing filters, to avoid leakage of non-periodic signals. Transient and exponential windowing functions are selected for excitation and response signals, respectively. Also, overlapping of windowed signals is performed to enhance the quality of windowed signals.

Both signals (force and correspondent response) are measured in time domain and transferred into frequency domain using Fast Fourier Transformation (FFT). The transfer function is, then, calculated as the ratio of acceleration to force in frequency domain and called the Frequency Response Function (FRF). Arithmetic average of four impacts is calculated for each specimen test and the coherence function is calculated to ensure the repeatability of the individual FRFs. High values of coherence (near 1.0) confirms the obtained FRF resonant modes. Auto correlation and cross correlation functions for the measured signals are calculated to obtain the coherence function.

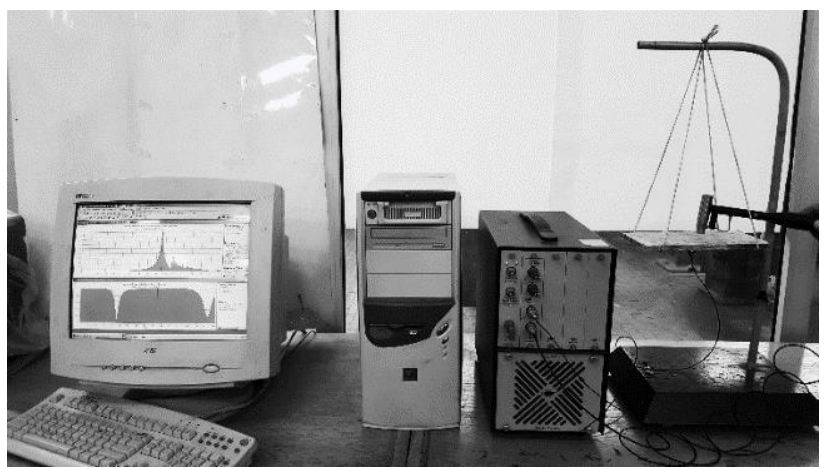

Figure 4. Modal testing setup of (TP) specimen.

The geometry and weight of the tested samples imposes constraints on the selected testing equipment to obtain accurate FRF results. For examples the weight of the accelerometer should be less than $10 \%$ of the specimen weight. Also, the location of measurement points, excitation points, and fixation point are ensured to be the same for all tested samples. All tests are conducted in room temperature to neglect any influence of temperature on the obtained damping and natural frequency of polyethylene constituent in composites [31].

\subsection{Flexure test}

Four-point flexural test is performed on a $5 \mathrm{kN}$ Mecmesin (MultiTest5-xt) testing machine according to ASTM D6272 [32, 33]. Quarter-point loading is applied at constant speed of $1 \mathrm{~mm} / \mathrm{min}$ on the tested specimen with a span of $160 \mathrm{~mm}$ between supports and 
span to thickness ratio of 16 . All tests are conducted at room temperature. Both support and loading radii are 5 $\mathrm{mm}$ as specified by the standard. An example of testing process is shown in figure 5 .

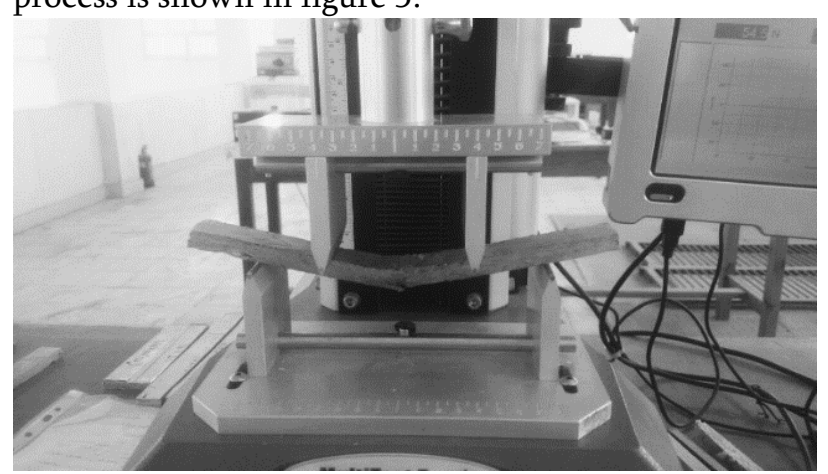

Figure 5. Setup for a 4-point flexural test on a particleboard specimen.

The measured cross-head displacement $(\delta)$, corresponding to the position of the loading support, have been recorded along with the total loading force $\left(2^{*} \mathrm{~F}\right)$. Both quantities have been used to calculate the section (E.I.) values based on equation (1).

$$
\begin{aligned}
& \delta=\frac{-F \cdot a \cdot\left(3 L x-3 x^{2}-a^{2}\right)}{6 \cdot E . I} \\
& a \leq x \leq L-a
\end{aligned}
$$

Where: $(\mathrm{L})$ is the span length, $(\mathrm{x})$ is the position along the specimen span, (a) is the distance from the end support to the loading position (L/4), (E) is the modulus of elasticity, (I) is the second moment of area.

It should be noticed that the cross section of the tested beam has been considered homogeneous with respect to the resistance to flexural stresses on the structure scale, despite the local heterogeneity caused by the TP strips, the wood plies, or the MDF particles. This is a common approach in the evaluation of wood elastic properties [33]. In order to calculate the modulus of rupture (MOR), equation (2) is used:

$$
M O R=\frac{3 \cdot F_{\max } \cdot L}{4 \cdot b \cdot h^{2}}
$$

Where: (Fmax) maximum load at each loading support, (L) span length, (b) specimen width, (h) specimen depth. Three specimens have been employed to determine the average modulus of elasticity MOE and the modulus of rupture MOR for the tested composite specimens. Table 2 summarizes the average specimens' cross-section dimensions. Higher dimensional inaccuracies are recorded in case of TP and TPFG specimens due to the nature the surfaces, in addition, to the difficulties encountered during cutting of the specimens. High degree of repeatability is obtained within the tested sets. Maximum deviations of $2.1 \%$ in $\mathrm{MOE}$ and $4.5 \%$ in the MOR have been recorded.

Table 2. Dimensions and deviations of flexural test specimens.

\begin{tabular}{ccccc}
\hline $\begin{array}{c}\text { Specimen } \\
\text { Material }\end{array}$ & \multicolumn{2}{c}{$\begin{array}{c}\text { Cross-Section } \\
\text { Dimensions }\end{array}$} & \multicolumn{2}{c}{$\begin{array}{c}\text { Max. } \\
\text { Dimensions } \\
\text { Deviation }\end{array}$} \\
\cline { 2 - 5 } & $\mathrm{b}$ & $\mathrm{h}$ & $\Delta \mathrm{b} \%$ & $\Delta \mathrm{h} \%$ \\
\hline TP & 24.7 & 11.8 & 1.2 & 0.9 \\
\hline TPFG & 24.1 & 11.8 & 1.5 & 0.8 \\
\hline MDF & 24.9 & 12.25 & 0.3 & 0.2 \\
\hline PB & 24.9 & 11.8 & 0.4 & 0.2 \\
\hline
\end{tabular}

\section{Results and discussion}

Figures 6 and 7 show the results obtained from modal testing of the specimens in the form of FRF magnitude and corresponding coherence function. The frequency range of interest for tested specimens is found within 0 $-1600 \mathrm{~Hz}$, where the first mode of vibration falls. For the fundamental resonant mode, the damping ratio $(\xi)$ is used to represent the damping capacity of each specimen. The results of modal testing conducted on identical specimens of the selected materials are shown in figures 8 and 9.

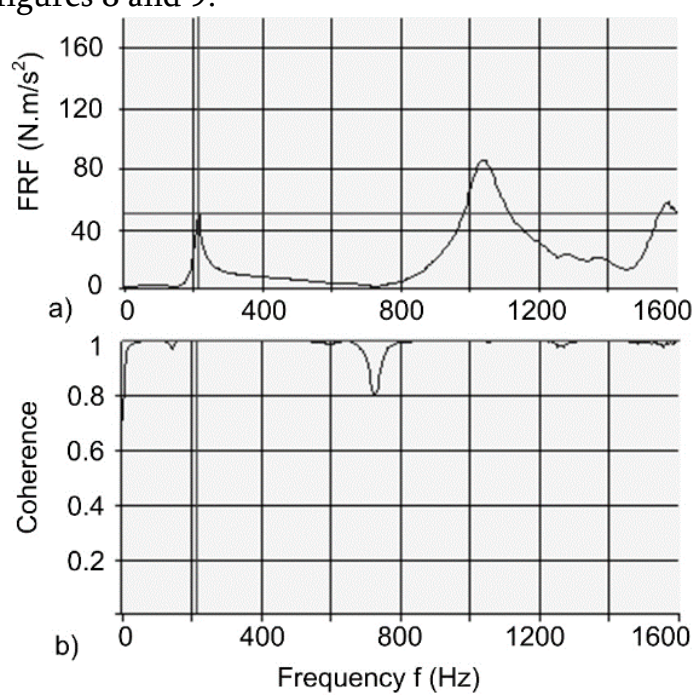

Figure 6. FRF and corresponding coherence function for TP. 


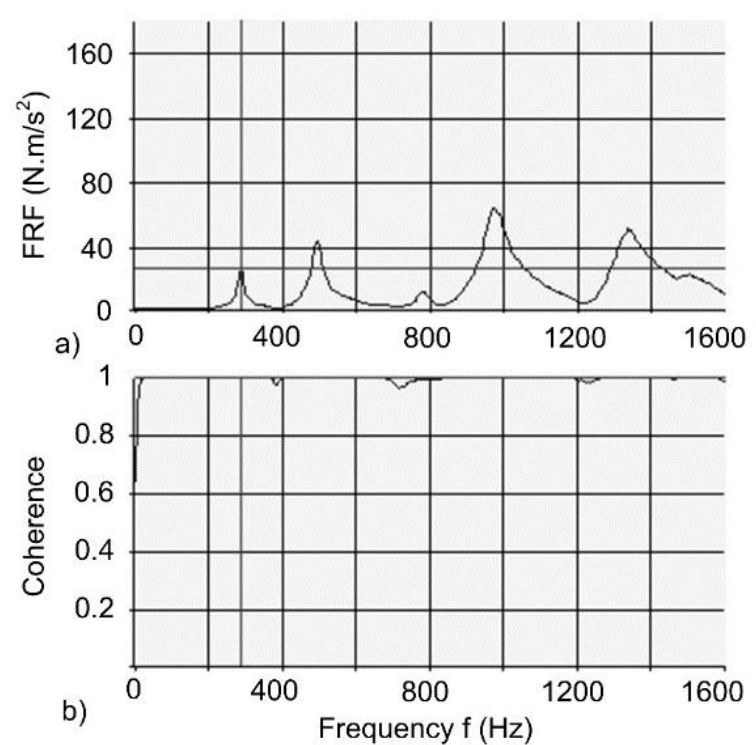

Figure 7. FRF and corresponding coherence function for TPFG.

It is important to note that the developed composites have orthotropic properties and therefore, the direction of impact loading during modal testing of the material is not influenced by a directionality in properties.

Figure 8 clearly shows that the damping ratios of the TP and TPFG are significantly higher than those of the materials of comparison. The values of damping ratio of $\mathrm{TP}$ and $\mathrm{TPFG}$ are $3.52 \%$ and $4.15 \%$ respectively which are higher than that of MDF by about $35 \%$ and $45 \%$. Particleboard material shows a damping ratio of $2.9 \%$ which is considerably lower than those of TP and TPFG. Figure 9 shows that the natural frequency of TP, and TPFG fall within the same range of values as for MDF and particleboard, levelling at an average of $300 \mathrm{~Hz}$. This indicates that TP and TPFG possess comparable dynamic stiffness to those of MDF Particleboard which make them suitable for common applications.

On the other hand, static stiffness, indicated by Modulus of Elasticity MOE results, are demonstrated in figure 10. TP and TPFG has MOE values around 1.8 $\mathrm{GPa}$ and $1.9 \mathrm{GPa}$ which are 24-28 \% lower than particleboard and by around $60 \%$ than MDF. This indicates that TP and TPFG falls in the same category as particleboard. The results of modulus of rupture MOR are shown in figure 11. The bending strength of TP and TPFG are around 11.6 MPa and 20.1 MPa respectively, which are higher by around $32 \%$ and $63 \%$ as compared to particleboard. The figure also shows that MOR of TPFG is about 0.90 the value of MDF, whereas it amounts three folds the value of MOR of particle board material.

The viscoelastic behaviour of the polymeric base of TP shows higher damping properties as compared to
WPC. The TP matrix is a mixture of polyethylene and paperboard. Polyethylene, as a thermoplastic constituent in TP specimens, is a contributor enhancing the damping capacity of specimen, however, it shows low stiffness values [20]. Paperboard, on the other hand, is known for its shock absorbent abilities and high damping capacities [34].

The molecular motion within the viscoelastic TP laminated matrix dissipates the internal shear energy, resultant from the impact loading, in the form of heat [35]. In addition, structural imperfections in TP, such as discontinuities between matrix constituents, lead to interfacial rubbing and hence contributes to more energy losses under dynamic loading conditions.

In case of TPFG, the addition of stiff glass skin to low-density TP core improves the strength, represented by MOR results, as compared to TP specimens. However, because TP laminates volume fraction is dominant in the specimen; therefore, the addition of glass skin has low influence on the MOE and natural frequency results compared to other TP specimen types. The internal heat generation capacity in the laminated structure and Glass fiber improve the damping characteristics of the TPFG specimens, as shown in figure 8.

For the explanation of MOR results, the failure modes of the different specimens are observed using the failed bent specimens, as shown in figures 12-15. The fracture of TP and TPFG starts by a crack initiation at the discontinuity points between staked layers at the surface of specimens. During bending, the crack propagated in between layers to the core of specimen leading to a cohesion debonding failure, as shown in figure 12 .

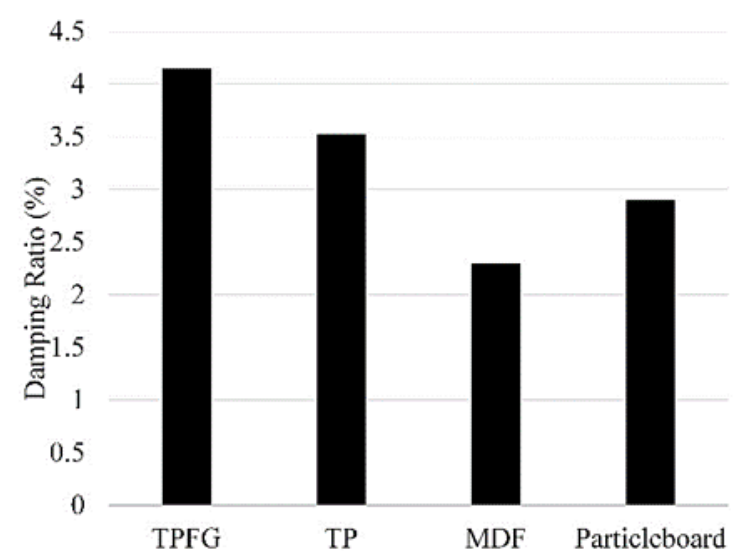

Figure 8. Damping ratio for the tested specimens. 


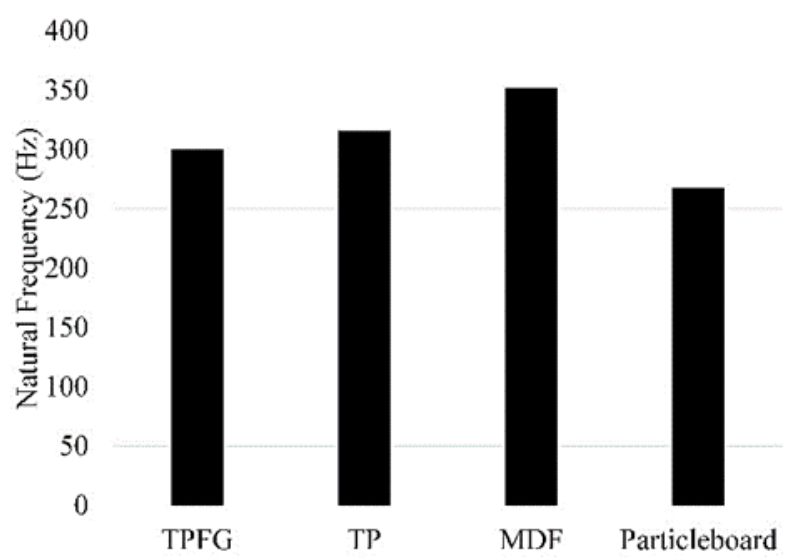

Figure 9. Natural frequency for the tested specimens.

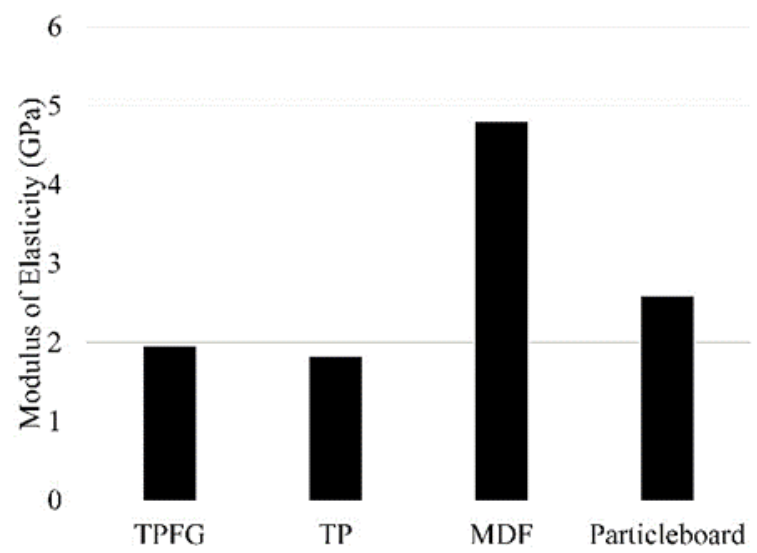

Figure 10. MOE results for the tested specimens.

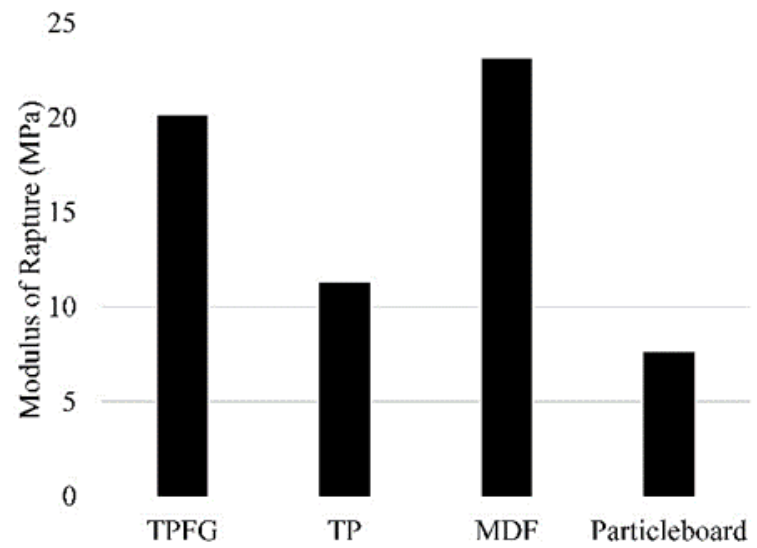

Figure 11. MOR results for the tested specimens.

TPFG is basically a sandwich material by adding two surface skin layers from fiber glass, and hence, this increased the specimen strength by $44 \%$ as compared to TP. However, insufficient cohesion between the glass skin and the TP core due to the lack of sufficient polyethylene resulted in a similar debonding failure mode to TP, in addition to delaminating between fiber glass woven fabric as a skin and TP core, as shown in figure 13. In comparison, the failure mechanism for particleboard is quite different, as shown in figure 14 .

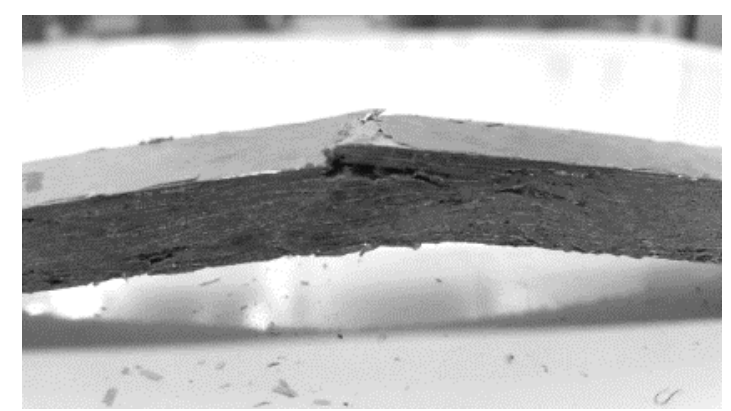

Figure 12. Flexural fracture of TP specimen.

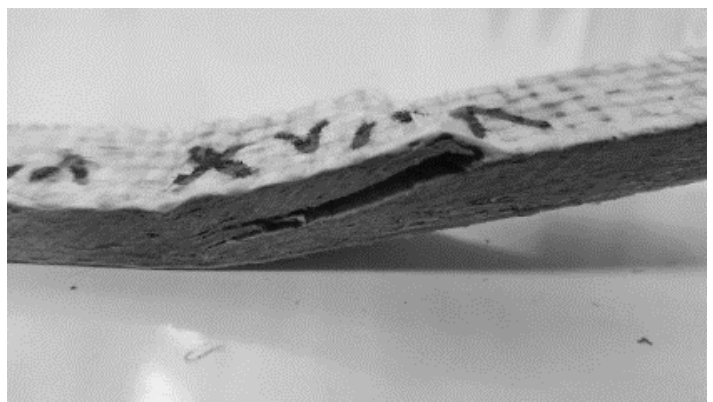

Figure 13. Flexural fracture of TPFG specimen.

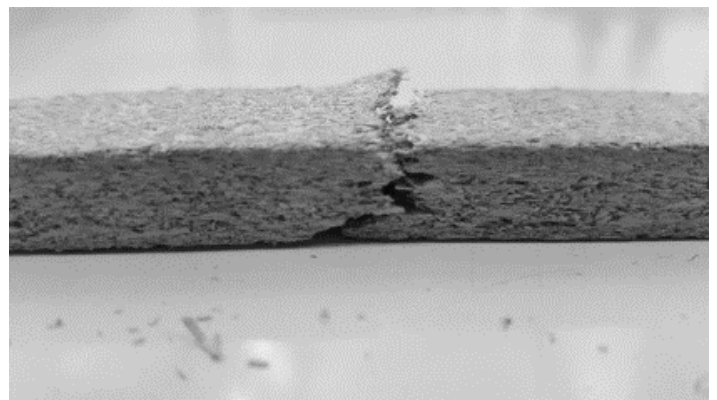

Figure 14. Flexural fracture of PB specimen.

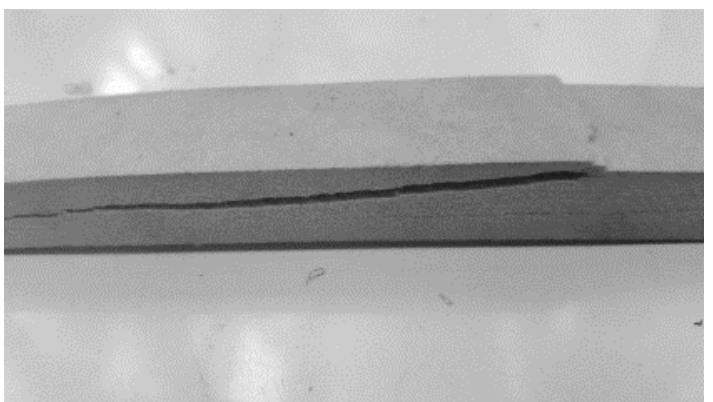

Figure 15. Flexural fracture of MDF specimen.

The cracks started at the surface and propagated slowly between the small wood particles resulting in a typical brittle failure shape. Shear failure is manifested in case of MDF sample under bending, as shown in figure 15. The fracture mode along with MOE results of figure 10 suggest low flexibility, and interfacial adhesion, which led to a debonding failure mode.

\section{Conclusions}

In conclusion, specimens made from TP and TPFG are found to possess higher dynamic characteristics in 
terms of damping ratio when compared to $\mathrm{PB}$ and MDF. Also, the results from bending test shows competitive MOR values of TP and TPFG. It is also clear TP show low stiffness values based on MOE results. The addition of glass fibers skin as reinforcement enhanced the strength values. The natural frequencies of TP and TPFG are close to those for MDF and particleboard which indicates comparable dynamic stiffness behavior. Future investigation focuses on studying the effect of shredding parameters, Polyethylene content, pressing pressure and holding time on the bonding strength and the dynamic characteristics of TP specimens. Also, the suitability of the material to acoustic isolation application is considered.

\section{References}

1. Martins G, Antunes F, Mateus AandMalça C. Optimization of a Wood Plastic Composite for Architectural Applications. Procedia Manufacturing 2017;12 pp 203-20.

2. Pizzo B, Macchioni N, Capretti C, Pecoraro E, Sozzi LandFiorentino L. Assessing the wood compressive strength in pile foundations in relation to diagnostic analysis: The example of the Church of Santa Maria Maggiore, Venice. Construction and Building Materials 2016;114 pp 470-80.

3. CRIBE partners with Magna to integrate wood fibre into automotive parts. Additives for Polymers 2012;2012(8) pp 5.

4. Ashori A. Wood-plastic composites as promising green-composites for automotive industries! Bioresource Technology 2008;99(11) pp 4661-67.

5. Stokke DDandGardner DJ. Fundamental aspects of wood as a component of thermoplastic composites. Journal of Vinyl and Additive Technology 2003;9(2) pp 96-104.

6. Kohl D, Long THNandBöhm S. Wood-based Multi-material Systems for Technical Applications -Compatibility of Wood from Emerging and Developing Countries. Procedia Manufacturing 2017;8 pp 611-18.

7. Hunt D. Properties of wood in the conservation of historical wooden artifacts. Journal of Cultural Heritage 2012;13(3) pp S10-S15.

8. Müller M, Militz HandKrause A. Thermal degradation of ethanolamine treated poly(vinyl chloride)/wood flour composites. Polymer Degradation and Stability 2012;97(2) pp 166-69.

9. Barton-Pudlik J, Czaja K, Grzymek MandLipok J. Evaluation of wood-polyethylene composites biodegradability caused by filamentous fungi. International Biodeterioration \& Biodegradation 2017;118 pp 10-18.

10. Mrad H, Alix S, Migneault S, Koubaa AandPerré P. Numerical and experimental assessment of water absorption of wood- polymer composites. Measurement 2018;115 pp 197-203.

11. Zhou A, Tam L-h, Yu ZandLau D. Effect of moisture on the mechanical properties of CFRPwood composite: An experimental and atomistic investigation. Composites Part B: Engineering 2015;71 pp 63-73.

12. TetraPak. Performance Data 2016: TetraPak; 2018 [updated March 2018. Available from: https://www.tetrapak.com/sustainability/environ mental-impact/a-value-chainapproach/sustainability-measuring-andreporting/performance-data.

13. Korkmaz A, Yanik J, Brebu MandVasile C. Pyrolysis of the tetra pak. Waste Management 2009;29(11) pp 2836-41.

14. Nyström T. Production of panel board - a world overview. TetraPak; 2000 August 2000.

15. Adrados A, de Marco I, Caballero BM, López A, Laresgoiti MFandTorres A. Pyrolysis of plastic packaging waste: A comparison of plastic residuals from material recovery facilities with simulated plastic waste. Waste Management 2012;32(5) pp 826-32.

16. Hassanin AHandCandan Z. Novel Bio-Based Composites Panels from TetraPak Waste. Key Engineering Materials 2016;689 pp 138-42.

17. Mohareb ASO, Hassanin AH, Candelier K, Thévenon MFandCandan Z. Developing Biocomposites Panels from Food Packaging and Textiles Wastes: Physical and Biological Performance. Journal of Polymers and the Environment 2016;25(2) pp 126-35.

18. Yilgor N, Köse C, Terzi E, Figen AK, Ibach R, Kartal SN, et al. Degradation Behavior and Accelerated Weathering of Composite Boards Produced from Waste Tetra Pak® Packaging Materials. BioResources 2014;9(3) pp.

19. Hassanin AH, Candan Z, Demirkir CandHamouda T. Thermal insulation properties of hybrid textile reinforced biocomposites from food packaging waste. Journal of Industrial Textiles 2016;47(6) pp 1024-37.

20. Treviso A, Van Genechten B, Mundo DandTournour M. Damping in composite materials: Properties and models. Composites Part B: Engineering 2015;78 pp 144-52.

21. Rangasamy S, Loganathan KandNatesan A. Experimental investigation and numerical analysis of the dynamic characteristics of a laminated hybrid composite bed. Polymer Composites 2015;38(1) pp 20-26.

22. El-Khatib AandNassef MGA. Advances in Modal Analysis Application. Journal of Vibration Testing and System Dynamics 2017;1(2) pp 153-66.

23. Nassef MGA, Elkhatib AandHamed M. Correlating the Vibration Modal Analysis Parameters to the Material Impact Toughness for Austempered Ductile Iron. Materials Performance and Characterization 2015;4(1) pp 12. 
24. Kouroussis G, Ben Fekih LandDescamps T. Assessment of timber element mechanical properties using experimental modal analysis. Construction and Building Materials 2017;134 pp 254-61.

25. Hwang S-F, Yeh C-KandChung S-C. Inverse determination of elastic constants of composite materials. Polymer Composites 2009;30(5) pp 521-27.

26. Geweth CA, Khosroshahi FS, Sepahvand K, Kerkeling CandMarburg S. Damage Detection of Fibre-Reinforced Composite Structures Using Experimental Modal Analysis. Procedia Engineering 2017;199 pp 1900-05.

27. Park HSandOh BK. Damage detection of building structures under ambient excitation through the analysis of the relationship between the modal participation ratio and story stiffness. Journal of Sound and Vibration 2018;418 pp 122-43.

28. Yakout M, Elkhatib AandNassef MGA. Rolling element bearings absolute life prediction using modal analysis. Journal of Mechanical Science and Technology 2018;32(1) pp 91-99.

29. TetraPak. Packaging material for Tetra Pak carton packages. In: TetraPak, editor. 2018.
30. Carne T, Griffith DandCasias M. Support Conditions for Free Boundary-Condition Modal Testing2018.

31. Colakoglu M. Effect of Temperature on Frequency and Damping Properties of Polymer Matrix Composites. Advanced Composite Materials 2008;17(2) pp 111-24

32. Test Method for Flexural Properties of Unreinforced and Reinforced Plastics and Electrical Insulating Materials by Four-Point Bending. ASTM International.

33. Ross RJandUsda Forest Service FPL. Wood handbook : wood as an engineering material. U.S. Department of Agriculture, Forest Service, Forest Products Laboratory; 2010.

34. Guo Y, Xu W, Fu YandWang H. Dynamic Shock Cushioning Characteristics and Vibration Transmissibility of X-PLY Corrugated Paperboard. Shock and Vibration 2011;18(4) pp 525-35.

35. Gargallo L. Physicochemical Behavior and Supramolecular Organization of Polymers. In: Radic D, editor. Reports the physicochemical behaviour of polymers in solution, bulk, and at 2-D interfaces. 1 ed: Springer Netherlands; 2009. p. XIV, 242. 